\title{
Yield of soybean crop in function of soil compaction affected by tillage system on Oxisol of subtropical region
}

\author{
J. O. Pereira ${ }^{1 *}$, D. de Melo ${ }^{2}$, G. Richard ${ }^{3}$, P. Defossez ${ }^{4}$, S. L. Silva ${ }^{1}$, F. A. de Oliveira ${ }^{1}$, R. O. Batista ${ }^{1}$, A. R. G. \\ Garcia $^{1}$
}

${ }^{1}$ Universidade Federal Rural do Semi Árido - centro de Engenharia, UFERSA - CE - Av. Francisco Mota, 572, Bairro

Costa e Silva, CEP 59625-900 Mossoró - RN, Brasil

${ }^{2}$ UTFPR - Universidade Tecnológica Federal do Paraná, Medianeira PR, Brasil

${ }^{3}$ INRA, UR 272 Sols 2163 Av. de la pomme de Pin, CS 4001 Ardon, F-45075 Orléans, France

${ }^{4}$ INRA, UR 1263 EPHYSE, 71 Av. Edouard Bourlaux, F -33140 Villenave d'Ornon, France

\section{*Corresponding author: jodilon@ufersa.edu.br}

\begin{abstract}
The increase in conservation tillage offers possibles benefits of decreasing soil compaction risk by wheeling. The objective this work was to evaluate the effect of the minimum tillage and direct drilling system after four and eight yars of continuous no-tillaging, on the soybean yield in function of the soil density and organic matter content. This trial was carried out on Oxisol, at Parana, subtropical region from Brazil. The relationship between yield of soybean and tillage system was analyzed as function of the soil density and organic carbon using linear regression model. No-tillage system four years (NT4) and minimum cultivation system in eight years of no tillage (MT8) showed greater decrease in soil density on the surface layer as a function of time, respectively, $0.22 \mathrm{~g}$ $\mathrm{cm}-3(1.318-1.098)$ and $0.24 \mathrm{~g} \mathrm{~cm}-3$ (1.248 - 1.010). Adjust of response curves of soybean yield as function of soil density and organic matter describes strong positive contribution of organic carbon in soybean productivite on the NT4 system and describes no interference of soil density on this system. In both systems (NT8 and MT8), the soybean yield decreases with increasing soil density. Soil sub-surface management after continuous periods of no-tillage should be investigated.
\end{abstract}

Keywords: soil management, bulk density and organic matter.

Abbreviation: no-tillage during four consecutive years (NT4), minimum tillage (MT4) after four consecutive years with no-tillage, no-tillage during eight consecutive years (NT8), minimum tillage (MT8) after eight consecutive years with no-tillage.

\section{Introduction}

The Brazil advances to become the largest producer of soybeans in the world. This goal should happen with investments in more production technology. Although the total produced is still lower than the U.S., the productivity of Brazil is currently exceeding 3,106 kg / ha (CONAB, 2012) against 2,922 kg / ha of Americans (FAO, 2012), which characterizes the total acreage of 24, 2 million ha in Brazil versus 30.5 million ha in the USA. Compared to corn crop, although Brazil currently occupies the third position in the ranking of the largest producers of corn in the world, with a planted area of 15.2 million ha and yield of $4,799 \mathrm{~kg} / \mathrm{ha}$, the setting for the corn crop is different with respect to soybean because Brazilian climate is not favorable for increasing its productivity. The implementation of farming systems, depending on how they are adopted within the agricultural property, may affect crop productivity implemented and physical quality of agricultural soils as density, porosity and the reserves of organic matter. The study of the changes in soil bulk density and in organic matter produced by various cropping practices such as direct-drilling and minimum tillage is fundamental to our knowledge of the causes and effects of the soil compaction.

Research has shown that direct drilling system provides greater coverage in surface soil due to crop residue left during the harvesting operation (Diaz-Zorita et al., 2002; Alvarez and Steinbach, 2009). Although its benefit in improving the physical and structural properties of the soil is established (Blanco-Caqui et al., 2012), the questions remain about its impact on crop yield, since some research has indicated the trend decline in yields crops after several years of continuous direct drilling system (Botta et al., 2010). Conversely, there is few information available about the changes in the physical parameters of the soil and concentration of soil organic carbon affecting crop yields in intensive and non-intensive direct drilling system.

Queiroz et al. (2011) studying inter-relation between soybean yield and soil compaction in crop-livestock integration system concluded that from the linear and spatial point of view, the high grain yield can be explained by the number of grains per plant and soil macroporosity. 
The search for a cultivation system which improves the soil structure and makes possible the agricultural management sustainable and the environmental damages are reducing the maximum, is essential to the modern agriculture. In this context, it is necessary to adopt a system of tillage that contributes to improvement the soil quality, increasing the productivity of the cultures and reducing the final cost of production (Queiroz et al., 2011). Soil compaction has serious consequences on crop production and on the environment (Soane \& Van Ouwerkerk, 1994).

Conservation tillage is intended to leave residue on the soil surface, and may include minimum tillage (using disks or chisel plough, for example) or no-tillage (Dam et al., 2005), minimizes erosion, conserves water within the root zone, and improves soil productivity (Durr et al., 2001). This tillage system, which decreases or eliminates tillage operations and maintains greater amount of crop residue on the soil surface, is increasing worldwide and makes possible the quickest and efficient operations. Direct drilling is a type of conservation tillage where the soil is left undisturbed prior to planting, and weed control is accomplished primarily with herbicides (Miller et al., 1998). This practice of management increases the organic matter in the superficial layer, where the crops residues are concentrated by the absence of physical incorporation through soil mobilization (Franzluebbers, 2005 and Salvo et al., 2010). In this sense, the stratification of the organic matter in the profile is an indicative parameter of the soil quality (Brady and Weil, 2002 and Franchine et al., 2007). For some researchers, tillage effects on soil physical properties are variables. Benjamin (1993) concluded that the direct drilling system had as great or greater hydraulic conductivity as both the moldboard plow-disk tillage and chisel plow-disk tillage systems owing to either a greater continuity of pores or to water flow through a few very large pores. Azooz et al. (1996), in Northwestern Canada, found in the direct drilling retained more soil water than conventional tillage system. Bulk density is considered to be a measure of soil quality due to its relationships with other properties (eg., porosity, soil moisture, hydraulic conductivity, etc.). It depends on the specific gravity of the particles it contains and their arrangement. Since the specific gravity of the mineral portion of soils, is more or less constant, soil structure is chiefly responsible for fluctuations of soil bulk density.

Pereira et al. (2007) studied the different factors that may change with direct drilling (soil porosity, soil moisture, carbon content) and quantifying their impacts on soil mechanical properties, contributing to an evaluation of the possible benefit of direct drilling in decreasing soil compaction risk. Adoption and successful implementation of no-tillage is strongly dependent on the farmer's knowledge of the technology involved in such a system (Cavalieri et al., 2009).

Crop yield is affected by field characteristics and operations as soil strength, compaction, soil water, tillage and residue practices, time of field operations and soil fertility, which together influence emergence, root development and nutrient availability (Curnoe et al., 2001) The compaction of the soil arable layer can reduce the productivity of the cultures when the soil reaches high density and low porosity, making difficult the penetration of the roots and the storage of water (Queiroz et al., 2011). In this layer, the compaction of the soil has increasing in the last years and it became a factor limit for the increase of the productivity of the direct drilling systems sustainable in the soils of clay texture (Hakansson, 2005).

The Western region of the Paraná (Brazil) has, in common, soils with high contents of clay, with more trend to arrangement of the particles. These characteristics make them easily compact reducing the efficiency of the agricultural operations. (Castro Filho, 2002).

The soil compaction affects the soil physics-mechanics properties in bigger or less intensity, most times in the negative form, restricting the development of the roots of the plants, reducing the absorption of water and nutritious and affecting the yield of the cultures (Blaco-Caqui et al., 2012).

Little data are available on the changes in soil physical parameters and SOC concentration, affecting crop yield in intensively managed no-tillage systems, and with minimum tillage after no-tillage.

Our objective was to evaluate the effect of the minimum tillage and direct drilling at short-term and long-term, in the soil bulk density, organic matter content and in the soybean culture yield.

\section{Results and discussion}

\section{Soil bulk density and organic carbon}

Table 1 shows the soil bulk density and organic carbon content measured in two periods of soil collect after the drilling at three depths on the tillage system. Soil bulk density and the organic carbon content were measured to determine if significant difference existed after implementation of the tillage system.

All tillage systems decreased the soil bulk density significantly over the periods ( $p 1$ to $p 2$ ) at the three depths, except MT4 at 0.05-0.10 and NT8 at 0.10-0.20 (table 1, p within Ts $x$ d). Direct drilling on no tillage system four years induced a larger diminution at the surface from 1.318 to $1.098 \mathrm{~g} \mathrm{~cm}^{-3}$. Average bulk density was significantly lower in the surface layer $(0-0.05 \mathrm{~m})$ than the underlying layers at the second period (p2) of sampling. No tillage system four years NT4) and minimum cultivation system in eight years of no tillage (MT8) showed greater decrease in bulk density on the surface layer as a function of time, respectively, $0.22 \mathrm{~g} \mathrm{~cm}^{-3}$ (1.318 - 1.098) and $0.24 \mathrm{~g} \mathrm{~cm}^{-3}$ (1.248 - 1.010). Analyzing the effect from no-tillage systems at short-term and long term, on the soil bulk density at superficial layer on the end of the crop cycle (p2), we notice increase of $8,2 \%$ of NT8 regard NT4. These results are consequences of the strong reductiom of organic matter during the crop cycle. At this period organic carbon content decreased $20,9 \%$ of NT8 regard NT4 (Table 1). These results show evidence that organic matter tends to decrease on the mineral constituents in tillage system of long time.(Table 1). Regarding tillage systems NT4 and MT4 (Table 1 and Fig. 1) there is significant decrease in soil density on depths of 0 0.05 and $0.05-0.10 \mathrm{~m}$ except on period p2, depth of 0.05 $0.10 \mathrm{~m}$. These results suggest that the chisel plow benefited the reduction on soil density at this depth, maintaining fairly porous structure, since the soil sampling was carried out with few days after the soil management (period p1). 
Table 1. Bulk density $\left(\mathrm{g} \mathrm{cm}^{-3}\right)$ and organic carbon content $\left(\mathrm{g} \mathrm{kg}^{-1}\right)$ as function of the tillage system, soil depth and soil collect period p1 and p2.

\begin{tabular}{|c|c|c|c|c|c|c|}
\hline \multirow{3}{*}{$\begin{array}{l}\text { Tillage } \\
\text { system(Ts) }\end{array}$} & \multirow{3}{*}{$\begin{array}{l}\text { Depth } \\
\text { (m) }\end{array}$} & \multirow{2}{*}{\multicolumn{2}{|c|}{$\begin{array}{l}\text { Bulk density } \\
\text { Period(p) }\end{array}$}} & \multicolumn{2}{|c|}{ Organic carbon } & \multirow[b]{3}{*}{ Average } \\
\hline & & & & & & \\
\hline & & p1 & p2 & p1 & p2 & \\
\hline \multirow[t]{3}{*}{ NT4 } & $0-0.05$ & $1.318 \mathrm{Aa} A$ & $1.098 \mathrm{AaB}$ & $25.88 \mathrm{Aa} A$ & $32.15 \mathrm{AaB}$ & 29,01 \\
\hline & $0.05-0.10$ & $1.395 \mathrm{AbA}$ & $1.320 \mathrm{AbB}$ & 26.78 AbA & $25.33 \mathrm{AbB}$ & 26,05 \\
\hline & $0.10-0.20$ & $1.390 \mathrm{AbA}$ & $1.310 \mathrm{AbB}$ & $20.68 \mathrm{Ac} A$ & $20.00 A c B$ & 20,32 \\
\hline \multirow[t]{3}{*}{ MT4 } & $0-0.05$ & $1.105 \mathrm{BaA}$ & $1.010 \mathrm{Ba} B$ & $29.38 \mathrm{BaA}$ & $26.05 \mathrm{Ba} B$ & 27,71 \\
\hline & $0.05-0.10$ & $1.275 \mathrm{BbA}$ & $1.228 \mathrm{AbA}$ & $24.90 \mathrm{BbA}$ & $23.30 \mathrm{Bb} B$ & 24,10 \\
\hline & $0.10-0.20$ & $1.338 \mathrm{AcA}$ & $1.285 \mathrm{AbB}$ & $18.98 \mathrm{BcA}$ & $19.48 \mathrm{Bc} B$ & 19,21 \\
\hline \multirow[t]{3}{*}{ NT8 } & $0-0.05$ & $1.283 \mathrm{ACa} A$ & $1.188 \mathrm{CaB}$ & $28.60 \mathrm{Ca} A$ & $26.60 \mathrm{CaB}$ & 27,61 \\
\hline & $0.05-0.10$ & $1.375 \mathrm{AbA}$ & $1.283 \mathrm{ABb} B$ & $21.60 \mathrm{Cb} A$ & $22.53 \mathrm{Cb} B$ & 22,07 \\
\hline & $0.10-0.20$ & $1.355 \mathrm{AbA}$ & $1.318 \mathrm{Ba} A$ & $17.43 \mathrm{Cc} A$ & $18.65 \mathrm{Cc} B$ & 18,03 \\
\hline \multirow[t]{3}{*}{ MT8 } & $0-0.05$ & $1.248 \mathrm{Ca} A$ & $1.010 \mathrm{AaB}$ & $26.48 \mathrm{Da} A$ & $21.25 \mathrm{Da} B$ & 23,85 \\
\hline & $0.05-0.10$ & $1.395 \mathrm{AbA}$ & $1.295 \mathrm{AbB}$ & $21.98 \mathrm{Cb} A$ & $24.35 \mathrm{Db} B$ & 23,16 \\
\hline & $0.10-0.20$ & $1.348 \mathrm{AbA}$ & $1.258 \mathrm{AbB}$ & $20.05 \mathrm{Dc} A$ & $20.80 \mathrm{Da} B$ & 20,41 \\
\hline
\end{tabular}

Means with same uppercase letter in the column (for tillage system (Ts) within $d \times p$ ), same lowercase letter in the column (for depths (d) within Ts $\times p$ ) and same uppercase letter bold italic on the line (for period ( $p$ ) within $\mathrm{Ts} x \mathrm{~d}$ ) did not differ significantly by Tukey test at $p<0.05$.

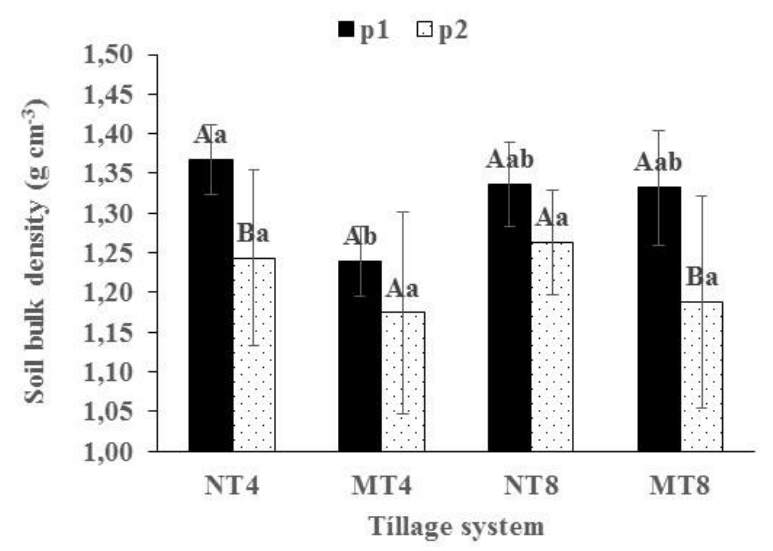

Fig 1. Soil bulk density in function of the depth in direct drilling tillage during four and eight years and minimum tillage after direct drilling of four and eight years (Period p1, one day after sowing; Period p2, sixty days after sowing. Values followed by the same uppercase letter (in the period) and lowercase (in the tillage system) do not differ statistically (Tukey test, $\mathrm{P}<0.05$ ).
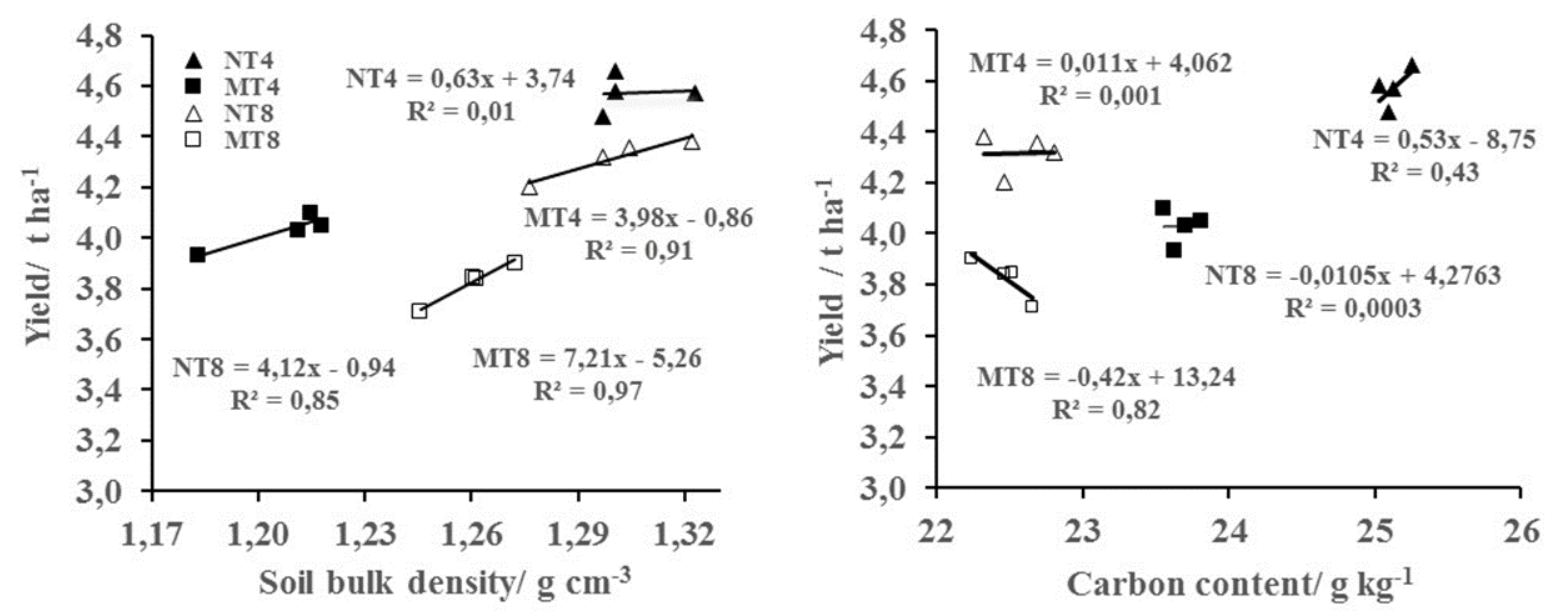

Fig 2. Linear regression models of soybean yield as a function of soil density and organic carbon in NT4, MT4, NT8 and MT tillage systems. 


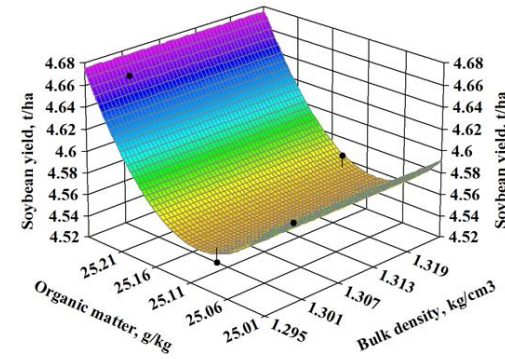

(a)

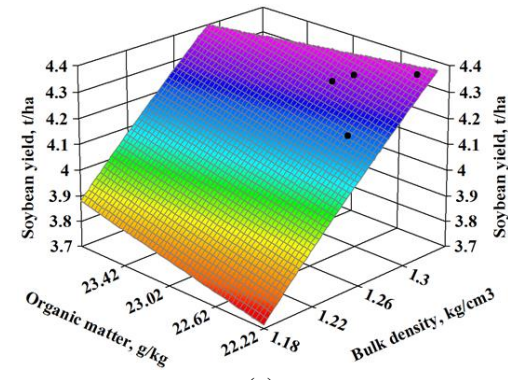

(c)

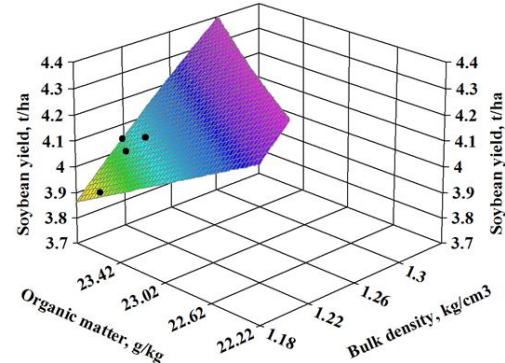

(b)

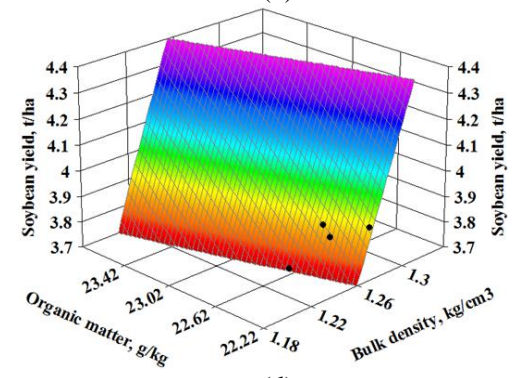

(d)

Fig 3. Soybean productivity in tillage systems: a) No-tillage four consecutive years, Yield $=a+b / O M+c * e^{-O M} ; a=259.5, b=-$ $6664, c=8.39 \times 10^{11} ; \mathrm{R}^{2}=0.96, \mathrm{p} /(a>0.207, b>0.211, c>0.219)$. b) Minimum tillage after four years of no-tillage consecutive, Yield $=a+\frac{b}{B D}+c * O M ; a=15.84, b=-6.73, c=-0.263, \mathrm{R}^{2}=0.99, \mathrm{p} /(a>0.084, b>0.068, c>0.179)$. c) No-tillage of eight consecutive years, Yield $=a+\frac{b}{B D}+c * O M ; a=7.53, b=-7.21, c=0.10, \mathrm{R}^{2}=0.99, \mathrm{p} /(a>0.052, b>0.043, c>0.157)$. d) Minimum tillage after eight years of no-tillage consecutive, Yield $=a+\frac{b}{B D}+c * O M ; a=11.87, b=-23.74, c=0.48, \mathrm{R}^{2}=0.98, \mathrm{p} /$ $(a>0.091, b>0.170, c>0.308)$.

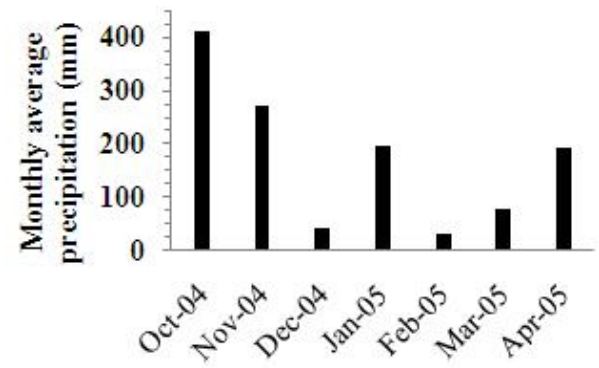

Fig 4. Precipitation from 2004 and 2005, average of the months of October to April. (After: Cooperativa Agroindustrial Lar, 2005).

Our results were consistent with those of the other studies as Dam et al. (2005), Mc Vay et al. (2006) and Alvarez and Steinbach (2009) which found that soil bulk density increased under no-tillage in relation to reduced tillage. However, have been contrary with those of Li et al (2011) had observed lower soil bulk density on no-tillage than conventionnal tilled, in experiments with more 20 years. Direct drilling generally induces an increase in bulk density in layers of depth below $10 \mathrm{~cm}$ due to energy from Wheel loading (Botta et al. 1999 and Botta et al., 2012). At the same depth there was a reduction in soil density in all tillage systems in $\mathrm{p} 1$ compared with $\mathrm{p} 2$. These results can have taken place, probably, because the samples from $\mathrm{p} 1$ were

collected one day after the sowing. Since the ground is very clay, obviously, it can have taken place the effect of load by wheeling, modifying the soil structure and increased its density. It is possible to be considered also that other sampling from $\mathrm{p} 2$ were carried out 60 days after the sowing and immediately after the harvest of the soybean. In this period there was sufficient time for the soil relaxation has been influenced by the effect of the action of plant roots, as well as of the free organic matter in the soil structure, which are the probable causes of decreased bulk density.

On average, organic carbon $(\mathrm{OC})$ concentration showing values NT4 greater than in MT4, MT8 and NT8, respectively, in all layers of the soil $(p<0.05)$ (Table 1). At the same depth, NT4 had higher concentration of organic carbon compared to NT8, indicating that the duration of use of no-till system did not generate increase in the concentration of organic carbon after 4 years. Also at the same depth, p1 showed higher tendency in the concentration of OC compared with p2 in all cropping systems, except NT4 depth 0 to $0.05 \mathrm{~m}$ (Table 1), which suggests the contribution of coverage of cultural remains at the soil surface before sowing. Variations 
in organic carbon throughout the period were likely related to the different times in the year that the soil samples were collected. Among the no-tillage systems, the results also reveal that NT4 pruduced values average of OC more uniforms, distributed in layers $0-0.05 \mathrm{~m}\left(29.01 \mathrm{~g} \mathrm{~kg}^{-1}\right)$ and $0.05-0.10 \mathrm{~m}\left(26.05 \mathrm{~g} \mathrm{~kg}^{-1}\right)$, with greater reduction in layer

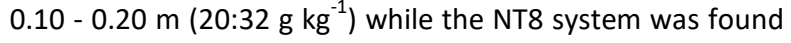
high concentration of $\mathrm{OC}$, only, in the $0-0.05 \mathrm{~m}(27.61 \mathrm{~g} \mathrm{~kg}$ $\left.{ }^{1}\right)$. When $O C$ is conpared among tillage systems as a function of the depth (Table 1), the results show that the organic carbon produced under NT4 was $4.7 \%, 21.6 \%$ and $5.1 \%$, respectivelly, higher than under MT4, MT8 and NT8 in the surface $(0$ to $0.05 \mathrm{~m}$ ) and $8.1 \%, 18.0 \%$ and $12.5 \%$ on depth $(0.05$ to $0.10 \mathrm{~m})$. These results indicate strong $\mathrm{OC}$ decrease trend in no-till system, the long time in the layers below the $0.10 \mathrm{~m}$. Thus, in general, our observation is that organic carbon below $0.10 \mathrm{~m}$ was not improved with minimum tillage system and has tended to decrease on no-tillage at long-time. All the systems appear to reach an equilibrium level at depth from $0.10-0.20 \mathrm{~m}$. The reflexes of these results are perceived in those of soil density (Table 1 ), since no change of soil compaction was observed on this layer.

On average, Viaud et al. (2011) found on 0-5 cm layer, relative difference in SOC stocks from $20 \%$, between shallow tillage and mouldboard ploughing and $15 \%$ for shallow tillage and no-tillage. Arvidsson (1998) and Ihmoff et al. (2004), studying influence of the organic matter on soil bulk density, noted that the compression ratio was not affected by the organic carbon content of the soil, whereas Pereira et al. (2007) found a positive correlation between the compression coefficient and the content of organic matter in the soil.

Our study shows tendency of better distribution of organic carbon in the layer 0 to $10 \mathrm{~cm}$ in cultivation systems in the short term option. Our results also reveal that organic matter tends to decrease strongly in the 10 to $20 \mathrm{~cm}$ layer over time in the no-tillage system (Table 1), NT4 and NT8. We understand that the reduction is associated to the repetitive effect of the load of the agricultural machinery in the operations of tillage along the years and the interaction with the soil texture, $62 \%$ of clay.

\section{Grain yield of soybean}

Soil Bulk density revelead weak positive correlation with soybean yield in NT4 $(r=0.10)$ and strong positive correlation in MT4 $(r=0.92)$, NT8 $(r=0.95)$ and MT8 $(r=$ 0.98), respectively (Fig. 2a), while, the organic matter revealed strong positive corelation with productivity in NT4 $(r=0.66)$ and strongly negative in MT8 $(r=-0.91)$. In other MT4 systems $(r=0.03)$ and NT8 $(r=-0.02)$, the organic matter was weakly correlated with productivity (Fig. 2b). Fig. $3 a, b, c$ and $d$ show the response curves of soybean yield as function of soil bulk density and organic matter in NT4, MT4, NT8 and MT8 systems, respectively. It observed in Figure $3 a$ that the fitted function $=259.5-\frac{6664}{O C}+8.39 *$ $10^{11} / e^{O C}$, of the NT4 system, describes strong positive contribution of organic carbon in soybean productivite. The function describes no interference of soil bulk density, in this system. In this case, for the studied parameters, the model suggests that for the richest soil in organic matter, there is tendency for most soybean productivity. In systems, MT4, NT8 and MT8, the fitting the response functions of production as a function of bulk density and organic matter had similar behavior, such as: Yield $=a+\frac{b}{B D}+c * O M$. Thus, for MT4, Yield $=15.84-\frac{6.73}{B D}-0.263 * O M$, NT8, Yield $=7.53-\frac{7.21}{B D}+0.10 * O M \quad$ and $\quad$ MT8, Yield $=$ $11.87-\frac{23.74}{B D}+0.263 * O M$ (figure $3 b, c$ and d). In tillage systems of eight years, the productivity function varies from a constant value plus the linear portion of the organic carbon. In both systems (NT8 and MT8), the increase of soybean yield decreases with increasing soil density. The adverse effects of soil compaction in soybean production are well described by the functions in these two systems. Our results show that the soil bulk density contributed with increment of 3.3 times on reduction of the soybean yield in MT8 (-23.74/BD) regarding MT4 (-7.21/BD), Fig. 3 c, d). Thus, in this study the regression models showed that soil bulk density and organic carbon content were well accepted as key indicators to estimate the soybean yield. Our results showed that the effect of cultivation practices in soybean production in the western region of Paraná was higher in the NT system than in MT, with NT4 showing higher production that NT8. It occurred relative increase in productivity of NT4 (4.58 t / ha) regarding to NT8 (4.34 t / ha), with increase of $5.5 \%$ in productivity. This difference was greater when contrasted NT4 (4.58 t / ha) with MT4 (4.04 t / ha) showing an increase of $13.24 \%$. These results highlight the need for the adoption of no-tillage in the region with same climatic characteristics and of soil, (Diaz-Zorita et al., 2002) observed that in general, no-till adoption, in the subhumid and semiarid Pampas is related to soil water conservation that allows adequate planting dates for maximal yields. Tanaka et al (1992) obtained growth in the productivity of the soybean, after the incorporation of leguminous plants like the crotalaria and the velvet bean and attributed such results to the reduction of the population of phytopathogenic nematodes, caused by the cultivation of these green manure sorts. However, our results contrast those obtained ones by Carvalho et al. (2004) that found greater productivity of soybean in the conventional tillage system under direct drilling system. For these authors the factor that can have contributed to greater productivity in the conventional tillage system went the lower soil density, resultant of this system which can have provided more growth of the plants roots and absorption of water and nutrients. In our case, probably, the smallest values of yield, in the soil from minimum tillage system, were caused by the low volume of rains, during the cycle of the culture (February to March, Fig. 4). In the soil from direct drilling system, the crop residue remains on the soil surface, avoiding the evaporation the water, the same does not happen with the soil from minimum tillage system, which ground is left unprotected and the evaporation is more accented.

\section{Materials and Methods}

The sampling was carried out in 2004/2005 at the agricultural Farm in Medianeira, western of State of Paraná $\left(25^{\circ} 20^{\prime} \mathrm{S}, 53^{\circ} 59^{\prime} \mathrm{W}\right)$, with height of $422 \mathrm{~m}$, South of Brazil. The soil was a Latossolo Vermelho, Brazilian classification (EMBRAPA, 2006), corresponding to an Oxisol, FAO (1975), with granulometry averaging 620,220 , and $160 \mathrm{~g} \mathrm{~kg}^{-1}$ for clay, silt, and sand, respectively. According to Koppen's 
system the climate is classified as Cfa (mesothermic), wet with a mean annual precipitation and temperature of 1955 $\mathrm{mm}$ and $23 \stackrel{\circ}{\circ} \mathrm{C}$, respectively.

The experimental area was constituted for four tillage systems: direct drilling with no tillage during four consecutive years (NT4); minimum tillage (MT4) after four consecutive years with no tillage; direct drilling with no tillage during eight consecutive years (NT8) and minimum tillage (MT8) after eight consecutive years with no tillage. In the NT4 and NT8 systems, the same machine sets were used and the same crops, soybeans (Glycine max (L.) Merr.) in the summer and maize (Zea mays L.) in the winter. The system was characterized like a succession of crops without rotation. The experimental site had been managed on conventional tillage with mouldboard ploughing to depth $0.20-0.30 \mathrm{~m}$ and harrowing before the implementation of the no tillage system.

Field operations with tractors Valtra $7854 \times 2$ TDA $55.2 \mathrm{kw}$, scarified, seeder varied according to tillage system. Proceeding as fertilizing, control of weeds and other treatments were carried out according to necessity and agronomic recommendations for the crops. With direct drilling, the crop residues were left on the soil surface, whereas, in the minimum tillage system, the residues were incorporated into the soil.

\section{Statistical analysis}

The experiment consisted of four randomized blocks constituting the 4 cropping systems and 4 repetitions within each block, with dimensions of $12 \mathrm{~m}$ of width for $50 \mathrm{~m}$ of length for each block. We use tri factorial design: tillage system (NT4, MT4, NT8 and MT8), soil sampling depth (0 to $0.05,0.05$ to 0.10 and 0.10 to $0.20 \mathrm{~m})$ and sampling period(p1 and $\mathrm{p} 2)$.

A total of 96 soil samples ( 4 tillage systems, 3 soil depths, 2 sampling period, and 4 replications) were collected in steel cylinders (inner diameter $70 \mathrm{~mm}$, height $24 \mathrm{~mm}$ ) and tested. The effects of these factors, as decisive variables, on soil bulk density and organic carbon were analyzed using ANOVA. For the significant $F$ case, the means were compared by Tukey test at $5 \%$ probability (SISVAR).

The relationship between yield of soybean crop and tillage system was analyzed as function of the soil bulk density and organic carbon using linear regression model to quantify the effect of these factors on crop productivity. The response curve fitting procedure for the factors-treatment was performed using the Table Curve software (JANDEL SCIENTIFIC, 1991).

\section{Soil bulk density and organic carbon}

The undisturbed soil samples were collected at depths of 00.05, 0.05-0.10, and 0.10-0.20 m using cores with an inner diameter of $70 \mathrm{~mm}$ and a height of $24 \mathrm{~mm}$ (Pereira et al, 2007). They were carried out in the laboratory of the course of Agricultural Engineering (UNIOESTE - Cascavel - PR Brazil). They were finally oven dried at $105{ }^{\circ} \mathrm{C}$ for $24 \mathrm{~h}$ to obtain dry soil mass. The dry bulk density was determined according to EMBRAPA (1997). Soil clods also were collected and wrapped in plastic for determination of soil texture and particle density (Monnier et al. 1973) and soil organic carbon (Raij et al., 2001)
The soil organic carbon content was determined colourimetrically by dichromate oxidation method as described by Raij et al. (2001). The analyses were determined in the laboratory of Soil of the Cooperative of Economical and Technological Development - (COODETEC Cooperativa de Desenvolvimento Econômico e Tecnológico, Paraná - Brazil - in Portuguese).

The dry bulk density and organic carbon content were determined with collect of the soil six day immediately after the sowing (period p1-November 3, 2004 in the systems NT4 and MT4, November 6, 2004 in the systems NT8 and MT8) and one hundred and ten days (110) after the sowing (period p2 - February 24, 2005 in the systems NT4 and MT4, February 28, 2005 in the systems NT8 and MT8), with four replications for each depth.

\section{Grain yield of soybean}

Grain yield was evaluated by means of manual harvest in all experiment. The track was effectuated in a stationary thrasher. Seeds were cleaned, weighed, and values were corrected for $13 \%$ moisture, after determination of grain moisture in a Vurroughf 700 grain-moisture analyzer, and transformed in $\mathrm{kg} \mathrm{ha}^{-1}$.

\section{Conclusion}

Direct drilling system long-term induces to an increase in the soil bulk density in the layer of subsurface depth. We have established effect of the relationships between the direct drilling system from four and eight years of continuous tillage and minimum tillage system after four and eight of direct drilling continuous, with the soil depth in the soil bulk density and organic matter. No-tillage system at long term showed at the superficial layer on the end of the crop cycle (p2), increase on the soil bulk density of $8.2 \%$ regard NT4. Duration of use of no-till system did not generate increase in the concentration of organic carbon (OC) after 4 years, showing values of NT4, greater than in MT4, MT8 and NT8, respectively, in all layers of the soil.

Our study shows tendency of better distribution of organic carbon in the layer 0 to $10 \mathrm{~cm}$ in cultivation systems in the short term option. Our results also reveal that organic matter tends to decrease strongly in the 10 to $20 \mathrm{~cm}$ layer over time in the no-tillage system. Adjust of response curves of soybean yield as function of soil bulk density and organic matter in NT4, MT4, NT8 and MT8 systems describes strong positive contribution of organic carbon in soybean productivite on the NT4 system. The function describes no interference of soil bulk density on this system. In both systems (NT8 and MT8), the soybean yield decreases with increasing soil density. The adverse effects of soil compaction in soybean production are well described by the functions in these two systems.

\section{Acknowledgements}

The authors thank the Coordenação de Aperfeiçoamento de Pessoal de Nivel Superior - CAPES (in Portuguese) for the scholarships and COODETEC for carrying out the soil chemical analysis support to this study and the São Jose Farm of Antonio José de Melo for offering the study area and logistics required in this work. 


\section{References}

Alvarez R, Steinbach HS (2009) A review of the effects of tillage systems on some soil physical properties, water content, nitrate availability and crops yield in the Argentine Pampas. Soil Till Res. 104: 1-15.

Arvidsson J (1998) Influence of soil texture and organic matter content on bulk density, air content, compression index and crop yield in field and laboratory compression experiments. Soil Till Res. 49: 159 -170

Azooz RH, Arshad MA, Franzluebbers AJ (1996) Pore size distribution and hydraulic conductivity affected by tillage in Northwestern Canada. Soil Sci Soc Amn J. 60: 11971201.

Benjamin JG (1993) Tillage effects on near-surface soil hydraulic properties. Soil Till Res. 26: 277-288.

Blanco-Caqui H, Claassen MM, Presley DR (2012). Summer Cover Crops Fix Nitrogen, Increase Crop Yield, and Improve Soil-Crop Relationships. Agron J. 104(1): 137-147.

Botta GG, Jorajuria CD, Draghi TL (1999) Soil compaction during secondary tillage traffic. Agro-Ciencia. 15: 139-144.

Botta GF, Tolon-Becerra A, Lastra-Bravo X, Tourn M (2010) Tillage and traffic effects (planters and tractors) on soil compaction and soybean (Glycine max L.) yields in Argentinean pampas. Soil Till Res. 110: 167-174.

Botta GF, Vázquez JM, Tolon Becerra A, Balbuena R, Stadler S (2012) Soil compaction distribution under land clearing in calden (Prosopis Caldenia Burkart) forest in Argentinean pampas. Soil Till Res. 119: 70-75.

Brady NC, Weil RR (2002) The nature and properties of soils. 13th ed. Prentice Hall, New Jersey, USA, p. 498-542.

Carvalho MAC, Athyde MLF, Sorato RP, Alves MC, and Arf O (2004) Soja em sucessão a adubos verdes no sistema de plantio direto e convencional em solo de cerrado. Pesqui Agropec Bras. 39: 1141-1148.

Castro-Filho C, Lourenço A, Guimarães MF, Fonseca ICB (2002) Aggregate stability under diferente soil management systems in a red latossol in the State of Parana, Brazil. Soil Till Res. 65: 45-51.

Cavalieri KMV, Silva AP, Tormena CA, Leão TP, Dexter AR, Hakansson I (2009) Long-term effects of no-tillage on dynamic soil physical properties in a Rhodic Ferrasol in Parana - Brazil. Soil Till Res. 103: 158-164.

CONAB - Companhia Nacional de Abastecimento (2012). Acompanhamento da safra brasileira de grãos: safra 2011/2012. Federação Brasileira de Plantio Direto na Palha._Portuguese. Available at: <http://www.conab.gov.br/Conabweb/download/pdf>. Accessed on: november 15, 2015.

Curnoe WE, Gregorich EG, Hayboe HN, Lapen DR, Topp GC (2001) Divisive field-scale associations between corn yields, management, and soil information. Soil Till Res. 58: 193-206.

Dam RF, Mehdi BB, Burgess MSE, Madramootoo CA, Mehuys GR, Callum IR (2005) Soil Bulk density and crop yield under eleven consecutive years of corn with different tillage and residue practices in a sandy loam soil in central Canada. Soil TillRes. 84: 41-53.

Diaz-zorita M, Duarte GA, Grove JH (2002) A review of no-till systems and soil management for sustainable crop production in the subhumid and semiarid Pampas of Argentina. Soil Till Res. 65, 1-18.

Durr C, Guerif J, Machet JM, Recous S, Richard G, Roger-
Estrade J (2001) A review of till effects on crop residue management, seedbed conditions and seedling establishment. Soil Till Res. 61: 13-32.

EMBRAPA - (Empresa Brasileira de Pesquisa Agropecuária) (1997) Manual de métodos de análises do solo, 2nd ed atual, Rio de Janeiro: EMBRAPA-SPI, 212 p.

EMBRAPA (Empresa Brasileira de Pesquisa Agropecuária) (2006) Sistema brasileiro de classificação de solos, 2nd edn. Rio de Janeiro: EMBRAPA-SPI, $306 \mathrm{p}$.

FAO (1975) UNESCO. Soil Map of the World (1/5000 000). FAO, Paris.

FAO (2012) FAOSTAT - Food and Agriculture Organization of the United Nations, - Available in: www.fao.org.br/Statistics Division.

Franchine JC, Crispino CC, Souza RA, Torres E, Hungria M (2007) Microbiological parameters as indicators of soil quality under various tillage and crop rotation systems in Southern Brazil. Soil Till Res. 92: 18-29.

Franzluebbers AJ (2005) Greenhouse gas contributions and mitigation potential in agricultural regions of North America: Introduction. Soil Till Res. 83: 1-8.

Hakansson, I., 2005. Machinery Induced Compaction of Arable Soils, Incidence -Consequences - Countermeasured. Swedish University of Agricultural Sciences, Reports from the Division of Soil Management, No. 109, Uppsala,- Sweden, 153 pp.

Imhoff S, da Silva AP, Fallow D (2004) Susceptibility to compaction, load support capacity, and soil compressibility of a Hapludox. Soil Sci Soc Am J. 68: 17-24.

JANDEL SCIENTIFIC (1991) Table curve: curve fitting software. Corte Madera, CA: Jandel Scientific, 280p.

Li L, Chan KY, Niu Y, Li G, Oates A, Dexter A, Huang G (2011) Soil physical qualities in na Oxic Psleustalf under diferente tillage and stubble management practices and application of S theory. Soil Till Res. 113: 82-88.

McVay KA, Budde JA, Fabrizzi K, Mikha MM, Rice CW, Schlegel AJ, Peterson

DE, Sweeney DW, Thompson C (2006) Management effects on soil physical properties in long-term tillage studies in Kansas. Soil Sci Soc Am J. 70: 434-438.

Miller JJ, Kokko EG, Kozub GC (1998) Comparison of porosity in chernozemic Clay loam soil under long-term conventional tillage and no-tillage. Can J Soil Sci. 78: 619629.

Monnier G, Stengel P, Fiés JC (1973) Une method de mesure de la densité apparente de petits agglomerats terreux: application à l'analyse des systems de porosité du sol. Annales Agronomiques. 24: 533-545.

Pereira JO, Defossez P, Richard G (2007) Soil susceptibility to compaction by wheeling as a function of some properties of a silty soil as affected by the tillage system. Eur J Soil Sci. 58: 34-44.

Queiroz RP, Lazarini E, Santos ML, Carvalho MP, Santos C (2011) Inter-relation between soybean yield and soil compaction under degraded pasture in Brazilian savannah. Rev Bras C Solo. 35:1579-1588.

Raij BV, Andrade JC, Cantarella H, Quaggio JA (2001) Análise química para avaliação da fertilidade de solos tropicais. Inst Agron. Campinas, 285 p.

Salvo L, Hernandez J, Ernst O (2010) Distribution of soil organic carbono in diferente size fractions, under pasture and crop rotations with conventional tillage and no-till 
systems. Soil Till Res. 109: 116-122.

Soane BD, van Ouwerkerk C (1994) Soil Compaction problems in world agriculture. In: Soil Compaction in Crop Production. Developments in Agricultural Engineering. 11 (eds. Soane BD, van Ouwerkerk C). pages 1-21. Elsevier, Amsterdam.
Tanaka RT, Mascarenhas HAA, Dias OS, Campidelli C, Bulisani EA (1992) Cultivo da soja após incorporação de adubo verde e orgânico. Pesqui Agropec Bras. 27: 1477-1483.

Viaud VDA, Angers DA, Parnaudeau V, Morvan T, Menasseri Aubry S (2011) Response of organic matter to reduced tillage and animal manure in a temperate loamy soil. Soil Use Manage. 27: 84-93. 